\title{
A Case Study of Anorexia \\ Nervosa and Obsessive \\ Personality Disorder \\ Using Third-Generation \\ Behavioral Therapies
}

\author{
Francisco Martín-Murcia', \\ Adolfo J. Cangas Díaz', \\ and Luisa Pardo Gonzalez'
}

\begin{abstract}
This article presents a case study of anorexia nervosa and obsessive personality disorder as a means of describing the main therapeutic interventions in the framework of "third-generation" therapies. The sessions were videotaped by independent observers. The particulars of the therapeutic relationship (based on functional analytic psychotherapy) and the contextual strategies (based on acceptance and commitment therapy) used are analyzed here. This case highlights progressive positive changes in social behavior, including congruence of values and vital actions, resolution of the eating disorder, greater openness to experience, and decreased pervasive thoughts. The discussion associates these changes with the types of intervention specific to this therapeutic approach.
\end{abstract}

\section{Keywords}

anorexia nervosa, eating disorders, functional analytic psychotherapy, acceptance and commitment therapy, single-case experiment

\section{Theoretical and Research Basis}

Eating disorders (EDs) pose a challenge for clinicians due to the difficulty of treating them, their morbidity, and their social impact. However, in cases of anorexia nervosa, this clinical significance has not been accompanied by implementation of improved psychological treatments (Agras et al., 2004). Although cognitive-behavioral therapy (CBT) or CBT-Enhanced (Karbasi, 2010 ) is clearly the approach with the highest proven efficacy for a wide range of psychological disorders, including ED, an effort to analyze and improve on existing cognitive-behavioral treatments must be made for the sake of patients who do not respond well to this type of intervention. It has even been suggested that randomized clinical testing is not pertinent until there is clear evidence of effective treatments for anorexia nervosa (Fairburn, 2005).

'University of Almería, Almería, Spain

Corresponding Author:

Francisco Martín-Murcia, Avda. Carlos III 432, $7^{\circ} \mathrm{J}$, Aguadulce, Almería, Spain

Email:murcia@cop.es 
The therapeutic difficulty that intervention entails in patients with EDs could be due to important, associated biomedical complications that can slow down or complicate treatment (Mehler \& Andersen, 1999); presence of dysfunctional family relationships (Martín-Murcia, Cangas, Pozo, \& Martínez, 2010) and the presence of high comorbidity (Martín-Murcia, Cangas, Pozo, Martínez, \& López, 2008; Ro, Martinsen, Hoffart, \& Rosenvinge, 2005; Rosenvinge, Martinussen, \& Ostensen, 2000). It seems only logical that the extensive psychopathology associated with EDs (not exclusively related to EDs' pathognomonic components) can easily alter the course and prognosis of such cases.

\section{Third-Generation Therapies}

The "third wave" of behavioral or cognitive-behavioral lineage (Hayes, 2004) that arose in the last decade is made up of a mixture of strategies whose philosophical principles come from a pragmatic, deterministic, phenomenological, and holistic or contextual perspective. Some have their own label: for example, acceptance and commitment therapy (ACT; Hayes, Strosahl, \& Wilson, 1999), functional analytic psychotherapy (FAP; Kohlenberg \& Tsai, 1991), dialectical behavioral therapy (Linehan, 1993), and mindfulness-based cognitive therapy (Segal, Williams, \& Teasdale, 2002). Both ACT and FAP are treatments based on a particular perspective on cognition and emotion. Essentially, they distinguish themselves from other classical models of psychopathology in that they do not necessarily assume that mental events (thoughts, emotions, or bodily states) cause problem behavior, suggesting alternative explanations to the classic $\mathrm{A} \rightarrow \mathrm{B} \rightarrow \mathrm{C}$ relationship. From this perspective, the patient is, on principle, not urged to modify and control negative events so as to free his or her mental state from them. Rather, he or she is instructed to accept such discomfort from a position of safety (distanced observation of the mind) and not to become obsessed with solutions that personal history has shown to be ineffective (Heffner \& Eifert, 2004). Acceptance theory (Hayes et al., 1999) is based on analyzing the personal costs to the patient of this evasive servitude and may even involve agreeing with the patient on the secondary benefits to his or her way of life. To analyze values not as goals but as life directions (Heffner \& Eifert, 2004) is one of the essential tasks of this therapy.

However, Kohlenberg and Tsai's $(1991,1994)$ therapeutic format is based on implementing certain principles of radical behaviorism into the everyday problems shared by many slowprogressing patients (within the framework of traditional personality disorders), such as difficulty with close relationships, isolation, alexithymia, low tolerance to criticism or failure, hostility, social phobia, or compulsive behavior. Their focus is mostly on contingencies that occur in vivo during sessions. They consider the therapeutic context and the patient's usual context as functionally equivalent, so they attend to problematic behavior and positive changes, while also attempting to develop more adaptive behavioral repertoires through natural reinforcement and molding. The observation that merely attending to behavior that is part of transfer facilitates improvement has led followers of this approach to suggest its functional use (Kohlenberg \& Tsai, 1991). This focus's operational components include searching for problem behaviors (clinically relevant behavior type 1), evoking them during the session, facilitating and reinforcing positive changes in behavior (clinically relevant behavior type 2), observing the reinforcing effects of therapy (which will vary depending on the individual and his or her problem and goals), and training the patient to functionally understand his or her problematic behavior (clinically relevant behavior type 3). In truth, analyzing the therapeutic relationship in this way would in large part account for the ubiquitous "common factors" of different psychological treatments. Even so, it is advisable to point out that although these tools can be used along with the most protocolized options within the CBT therapeutic arsenal, before doing so, certain philosophical questions should first 
be clarified, if only to sort out certain flagrant contradictions (Heffner \& Eifert, 2004; Wilson \& Roberts, 2002). For example, use of relaxation training would not necessarily seek relaxation or a state of happiness in and of itself; rather, it is a form of freedom, that is, of being able to act more comfortably in difficult situations (Wilson \& Roberts, 2002). Along this line of thought, Socratic dialogue, rather than being "a correct way of thinking," is a therapeutic activity that could enable a patient's thinking to become more flexible, enabling him or her to focus on the content of their thoughts from the necessary objective distance, thereby reducing cognitive defusion. Free association or dream telling might also be used even though they have no cognitive-behavioral pedigree, to elicit introspection if the patient usually avoids that type of activity; this does not necessarily require a "deeper" interpretation.

Several of these principles were implemented in the treatment of the clinical case described and analyzed in this study.

\section{Case Introduction}

A 17-year-old female presented with a 3-year diagnosis of anorexia nervosa and obsessivecompulsive disorder, as per the Diagnostic and Statistical Manual of Mental Disorders (4th ed., text rev.; DSM-IV-TR; American Psychiatric Association, 2000) criteria. Her personal history indicates that childhood sleep disorder and daily, emotionally triggered epileptic crises (syncope) began to arise significantly at age 7 in stressful situations (currently only elicited by very intense stress).

\section{Presenting Complaints}

Her patient history highlights that since age 14, she has exhibited depressed mood with anhedonia, sadness, and high levels of anxiety and irritability. Currently, activities that occupy her entire day are her studies, obsessively reviewing homework to the point of cognitive blockage, thinking about food, and controlling her image and weight by means of clothing, dieting, and comparing nutritional labels. She is on a hypocaloric diet, so she is constantly hungry. She has begun to binge and steal food. She also performs other compulsive rituals before going to bed or before studying to alleviate her anxiety and worries. For example, she sometimes has to start her homework all over if there is a spot or smear on her notes, regardless of whether it necessitates her starting from the beginning. She has constant doubts about her intellectual ability, self-deprecating thoughts about her image or person, and a desire to die or to leave school. She dwells on painful family and personal matters, past and present. She receives constant criticism and no sign of affection from her parents, who often argue. She experiences intense anger toward her father and compares him unfavorably to her mother (whom she identifies as a "failure lacking in courage"). However, she follows her father's rules by devoting herself exclusively to her studies, thereby avoiding any and all sources of pleasure also she complains about everything and everyone. She has no leisure activities and her not had any sexual experience. She continually compares herself with classmates, feeling underrated and afraid; has self-referential ideation, and avoids contact. The result of this is that she is made fun of (they call her "strange" and "nerd") and does not pay attention to her social surroundings. Finally, her greatest fear is not getting good-enough grades to go to college (the only value she expresses) and get away from her family.

\section{Session Problems (Clinically Relevant Behavior Type I)}

Table 1 displays problems manifested during sessions that served as discriminative behaviors with which the therapist intervened throughout treatment. 
Table I. Clinically Relevant Behavior Type I

\begin{tabular}{|c|c|}
\hline Clinically relevant behavior type I & Examples \\
\hline Hopelessness & $\begin{array}{l}\text { Says the therapist cannot help her; does not } \\
\text { discuss relevant subjects }\end{array}$ \\
\hline Intimacy-avoidance behavior & $\begin{array}{l}\text { Does not make eye contact with the therapist } \\
\text { or ask him personal questions, relays messages } \\
\text { with no affective tone, withholds information }\end{array}$ \\
\hline Constant demand for rules of behavior & "Tell me what I have to do when X happens" \\
\hline Limits commitment to and focus on therapy & $\begin{array}{l}\text { Only makes demands about how to improve her } \\
\text { academic performance, avoids mention of ED }\end{array}$ \\
\hline $\begin{array}{l}\text { Insists on using linear, logical mathematical } \\
\text { reasoning to establish a life project }\end{array}$ & "First study and then be happy" \\
\hline $\begin{array}{l}\text { Resists finding alternative explanations for her } \\
\text { problems }\end{array}$ & "Being thin makes me happy" \\
\hline $\begin{array}{l}\text { Discomfort when there is silence or lack of } \\
\text { response from therapist }\end{array}$ & "What happens is I do not know what to say" \\
\hline Complaint pattern & "It is too late, it is very difficult" \\
\hline $\begin{array}{l}\text { Excessive adherence to schedules and session } \\
\text { plans, records every detail of the day's events }\end{array}$ & Bring checklist of any matter \\
\hline Expresses bad mood and desperation & "Therapy cannot help";"I want to die" \\
\hline Parental interference in therapy & $\begin{array}{l}\text { Mother demands information about what is going } \\
\text { on in therapy, predictably refuses to cooperate, } \\
\text { and father refuses to continue spending money } \\
\text { on his daughter's treatment }\end{array}$ \\
\hline
\end{tabular}

Note: $E D=$ eating disorder.

\section{History}

At age 14, the client began to diet because she was slightly overweight and dissatisfied with her body, immediately assuming a rigid eating pattern. She then began treatment at a mental-health unit. Her avoidance behaviors include placing weights in her bra to falsify her weight at doctors' visits, dipsomania, lying about food, doing exhausting physical exercise, and enumerating somatic complaints was to eat less. At 16, she had to be hospitalized and a minimum weight and balanced diet were selected (though her actual diet was dissociated and hypocaloric). Following her hospitalization, the patient reported that psychologically she was the same or worse off and lost weight again (body mass index $[\mathrm{BMI}]=17$ ), restricting her food intake. Meanwhile, the tremendous stress of her academic demands only got worse (a brilliant academic record in her 2nd year of high school) to the point where she was devoting an average of $15 \mathrm{hr}$ a day to her studies (even on weekends). During a school trip last year, she began severe restriction and had her first episodes of stealing food from her roommates, binging, and purging. With regard to family dynamics, her parents' marital relationship is cold. The mother is pessimistic, is invasive, and has little ability to negotiate, and her predominant values relate to social image (comparisons, criticisms). In the last 8 months, the patient has been receiving psychological help solely to improve her study habits and techniques.

Finally, she has been treated with a tetracyclic piperazine-azepine derivative able to modify serotonergic and noradrenergic neurotransmission. It is an antagonist to serotonin receptors (5-HT), especially subtypes 5-HT2 and 5-HT3, and to alpha 2-adrenalin presynaptic receptors. There was no evidence of antidepressant or antiobsessive effect in the patient. This treatment was suspended before starting the present psychological treatment. 


\section{Assessment}

Informed consent from the patient and her family was received to record all sessions on video and use them as research material. An A-B design was prepared, with a baseline established during the month prior to treatment, and 3 weeks were set aside to create behavior checklists, evaluate the patient, and interview her family. There were 20 sessions over the course of approximately 9 months. All sessions were analyzed by researchers not involved in the treatment to record and classify the therapeutic intervention (conducted by the first author). Three follow-up sessions were held at 3, 6, and 12 months.

The Millon Clinical Multiaxial Inventory-III, (MCMI-III; Millon, 2007) is a questionnaire comprised of 11 clinical personality patterns scales, 3 severe personality pathology scales, 7 clinical syndromes scales, and 3 severe syndromes scales. It also includes 4 correction scales to measure response validity such as sincerity, desirability, and deliberately exaggerated symptomology.

The Eating Disorder Inventory (EDI; Garner, 1998) is a self-report instrument widely used to evaluate the symptoms that typically accompany anorexia nervosa and bulimia nervosa. It provides scores on 11 scales that are clinically relevant to EDs. The revised version of the EDI (EDI-2) retains the original version's 64 items and adds an additional 27 items that constitute three new scales: Asceticism, Impulse Regulation, and Social Insecurity.

We also designed a questionnaire about values and the consistency with which respondents' actions adhere to their values, in addition to recording their behavior and life experiences.

Table 2 shows a functional analysis that synthesizes the main circumstances involved in the acquisition and maintenance of certain variables.

\section{Case Conceptualization}

We sought to clarify the patient's explanations of and hypotheses about her problems, along with her concepts about life, happiness, how to achieve her goals, the self and others, and maladaptive thought patterns. She exhibited intense cognitive defusion, identifying every mental event as a reality, and also exhibited dichotomous thought patterns, selective abstraction, overgeneralization, and strong cognitive rigidity. The only life value expressed in her original evaluation was academic success, and she identified happiness in terms of behavioral control (e.g., sticking to a diet and getting good grades). Any reinforcement provided by social recognition was due to her academic success and the "perseverance and effort" required to keep her grades up. She expressed no interest or positive feelings toward her parents and considered them to blame for her personality.

We decided on three areas of her life to change. In the area of EDs, the therapeutic goals included adopting unrestricted eating patterns (forbidden foods), stopping control behavior (reading labels, eating diet foods, weighing herself, measuring herself by her clothes), and preventing binging and purging (which the patient was especially worried about). Her personal and social goals were to generate a trusting relationship with a male outside her family circle (the therapist), to increase her frequency of verbalization, to clarify her values, to learn not to follow rules (in the form of compulsive rituals or self-justification, for example), to open herself up to experience, not to avoid spontaneous initiatives, to initiate social activities, and to increase the probability of successfully completing her schooling. The established family goals were to neutralize alarming verbal conduct; to ease up on the rule-following model; to avoid interfering with subjects of therapy, especially EDs; and to train the patient not to enter into symmetrical escalation (disruptive interaction with parents). 


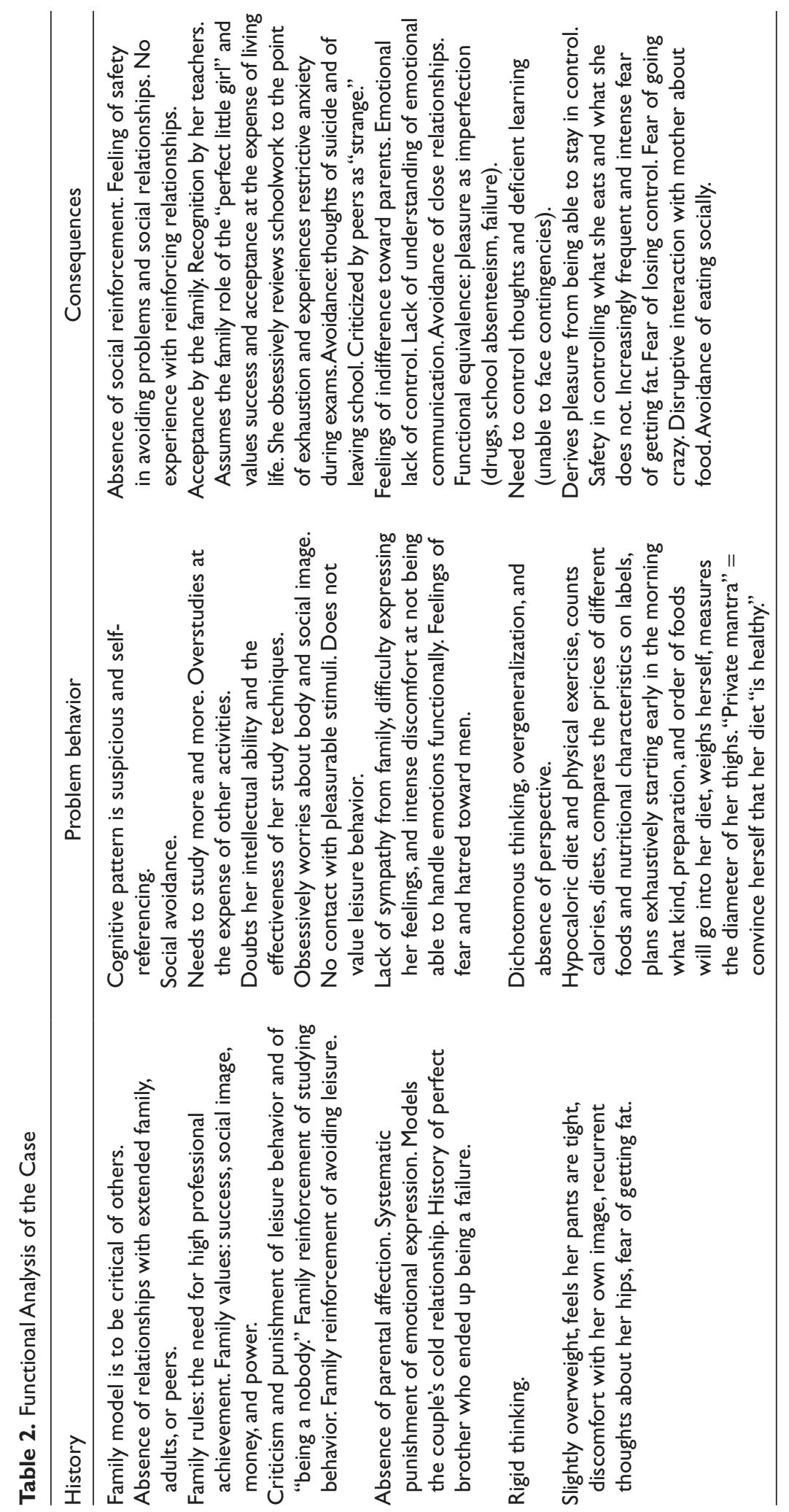




\section{Course of Treatment and Assessment of Progress}

The approach had essentially an FAP format with ACT components; so the first sessions were devoted to constructing a suitable therapeutic alliance. An attempt was made to interest the patient in facilitating an alliance through immediate reinforcement of her narrative verbal behavior, making use of humor, and modeling through warm, affective behavior. The intervention essentially reinforced clinically relevant behavior type 2, which involves adaptive social behavior and intimacy (making eye contact with the therapist, bringing him gifts, gestures of fondness, and respecting turn-taking and the therapist's ideas even when she did not agree with him). Sessions held with her parents made it clear (to them and the patient) that the therapist would be in control, that the parents should abstain from intervening in key subjects of treatment (EDs, studies, and social relations), and that the therapy would be based on absolute confidentiality. The therapist's image was reinforced by forging one of the few intimate relationships the patient had that was shielded from the usual family interference. She was instructed to stop her disruptive behavior by extinguishing aggressive responses, and she was provided with information about when, how, and why they are prompted to occur. Confrontations were used to bring the patient into direct contact with her own contradictions (e.g., observing the differences between what she says and what she does) and to strike a balance between the cost and the usefulness of her behavioral repertoire. Resources were called on-such as personal examples or anecdotes about other patients - to broach certain subjects, to bring up clinically relevant matters, and to open her up to a new narrative about values (hidden or avoided at first to alleviate suffering). Functional interpretations were reinforced (alternatives to her logic), facilitated by the delivery of technical information (on cognitive overload, biorhythms, consequences of restricting food, etc.), by the use of paradoxes (e.g., "control is the problem"), and by utilizing metaphors and analogies (e.g., "Salmon struggle upstream to achieve their primary goal, and thus, make the downhill trip calmly and peacefully, pleased to have achieved something of value"; "A small splinter in the foot of the majestic lion can turn it into a vulnerable kitten, and removing that little piece of wood can revive the magnificent lion"; "The story about the centipede that could not walk because he stopped to think about how he did it").

Socratic dialogue was also used (a reinforcing activity in and of itself due to the patient's taste for reflection) as an opportunity to reinforce her understanding (clinically relevant behavior type 3), to make her aware that "any idea or hypothesis can be built on reality," and to allow her to distance herself from the content of her thoughts. During sessions, we modeled and reinforced the behaviors of being open to experience, improvising, and accepting and normalizing emotions (encouraging the patient to experience her fears of gaining weight or failing, and verbalize her feelings toward the therapist). She accepted the risk that she may at first not be able to achieve her goal of getting good-enough grades to study what she wants in college. Furthermore, we tried to reinforce her interest in continuing the process of personal change by accepting risk by pointing out that in the second quarter of her treatment, her grades were similar to her previous academic record but her way of life had changed for the better.

Table 3 records the frequency of the therapist's various interventions.

\section{Assessment of Progress}

Changes observed were separated into those pertaining to scores on questionnaires and those referring to problem behavior. Table 4 shows the difference in her MCMI-III scores, emphasizing the scales related to social behavior (Schizoid, Dependent, Paranoid) and mood (Anxiety, Depression). The relative importance of different values changed, promoting those related to her social life (leisure, entertainment, social relations, partner), moderating those related to work 
Table 3. Frequency of Therapist's Behaviors

\begin{tabular}{lr}
\hline Therapist's behaviors & $M$ \\
\hline Psychoeducation, confrontation, unbalancing, clarifying, life-cost analysis, conveying & 27 \\
therapist's own "mistakes" and "failures" & 5 \\
Reinforces openness to experience, changing social avoidance, mental distancing. & 17 \\
Extinguishing ED issues (weight, image, food, fashion) & 3 \\
Metaphors, analogies and paradoxes, personal examples from therapist's private life, & I \\
revelations, imagination, biographical examples, role-playing & 4 \\
Taking responsibility (behavior checklists, experiential exercises, homework, does not & 3 \\
give directions) & 3 \\
Socratic dialogue & \\
Modeliving (instruction) & \\
Normalizes private events & \\
\hline
\end{tabular}

Note: $\mathrm{ED}=$ eating disorder.Average per session.

Table 4. MCMI-III Scores

\begin{tabular}{|c|c|c|}
\hline MCMI-III scales & Start & End \\
\hline Schizoid & 60 & 0 \\
\hline Avoidant & 70 & 9 \\
\hline Depressive & 73 & 9 \\
\hline Dependent & 61 & 15 \\
\hline Histrionic & 44 & 102 \\
\hline Narcissistic & 13 & 74 \\
\hline Antisocial & 56 & 45 \\
\hline Aggressive & 52 & 24 \\
\hline Compulsive & 51 & 36 \\
\hline Negativistic & 68 & 20 \\
\hline Self-defeating & 59 & 9 \\
\hline Schizotypal & 64 & 5 \\
\hline Borderline & 72 & 5 \\
\hline Paranoid & 62 & 5 \\
\hline Anxiety & 79 & 5 \\
\hline Somatoform & 64 & 5 \\
\hline Bipolar & 63 & 35 \\
\hline Dysthymia & 77 & 5 \\
\hline Alcohol dependence & 57 & 65 \\
\hline Drug dependence & 57 & 35 \\
\hline Posttraumatic stress & 62 & 5 \\
\hline Thought disorder & 67 & 5 \\
\hline Major depression & 64 & 5 \\
\hline Delusional disorder & 66 & 5 \\
\hline Debasement & 81 & 0 \\
\hline
\end{tabular}

Note: MCMI-III = Millon Clinical Multiaxial Inventory-III.

and education, and decreasing those related to body image (diet, physical exercise). Similarly, her final EDI-2 scores were not clinically significant and her eating behavior and anthropomorphic parameters were normalized, with a BMI of 22 (Figure 1). Regarding her social and family behavior, an increase was observed in social activities, making friends, and leisure activities. 


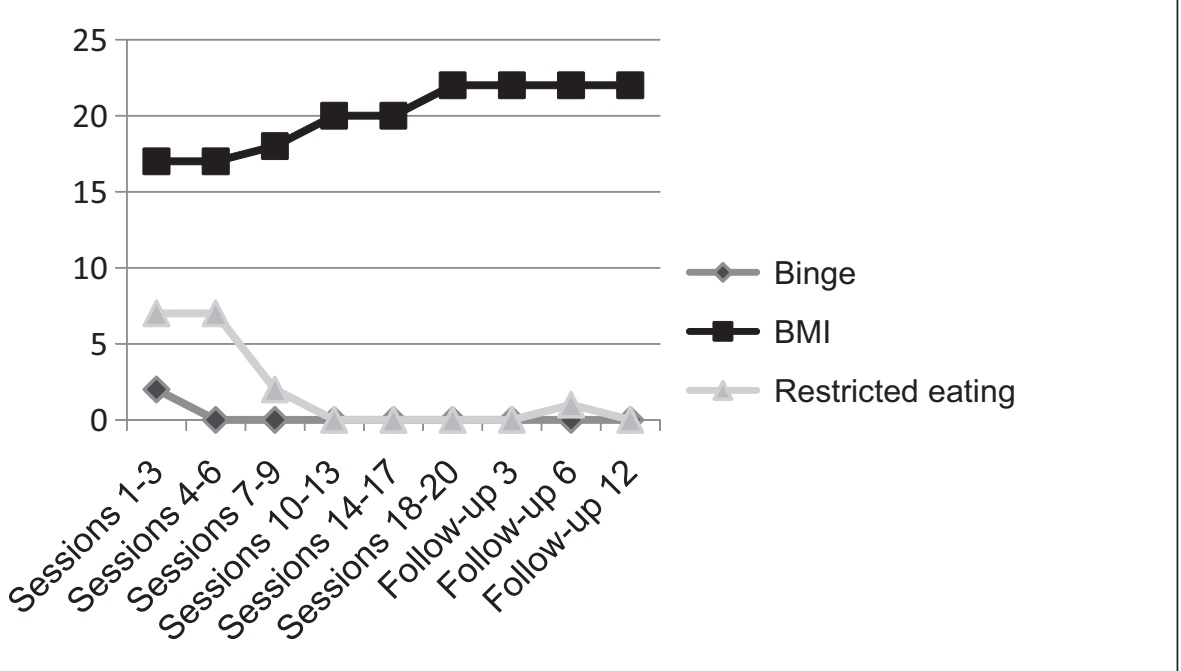

Figure I. Body mass index (BMI) and progression of eating behavior

\section{Complicating Factors}

Two complicating factors were detected. On one hand, the father refused to pay for treatment, even though it posed no real economic problem. The patient's mother took over the responsibility of paying for sessions. We believe that the father's refusal was due to the fear of losing control over his daughter, who in the end would cease to have school as her only existential issue and he would not get what he wanted, a successful daughter. On the other hand, the mother attempted to prevent her daughter from going away to college far from the family's residence.

\section{Access and Barriers to Care}

How medical care was managed should not be left out. The patient's mother worked for Public Health Services, so the means to pay for therapy was available.

\section{Follow-Up}

The follow-up evaluation consisted of clinical interviews, gathering information from the family, and the same tests that were administered pretreatment (6-month follow-up). Evaluation was carried out at 3,6, and 12 months, at which time it was established that the patient had begun to have close relationships in addition to a stable partner. A drastic decrease in disruptive family behavior also occurred (Figure 2). It may be said that her academic performance ultimately (last quarter of the year and her university entrance exams) improved over her prior grade-point average, so the patient did in fact earn the grades she needed, and is currently in college studying toward the degree of her choice. Twelve months after treatment, the patient maintained a BMI of 22 and exhibited no restrictive eating or binging.

\section{I Treatment Implications of the Case}

One implication of this study is that further research is needed on the efficacy of CBTs for individuals with EDs, particularly anorexia nervosa. Most studies of EDs and CBT have targeted 


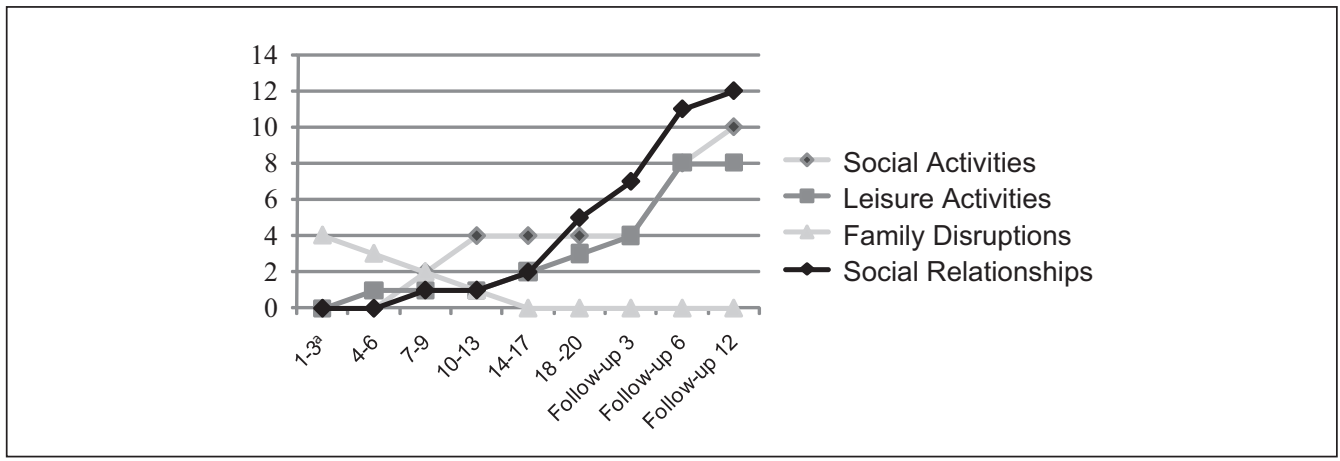

Figure 2. Progression of family and social behavior

aNumber of sessions.

patients with bulimia nervosa. What is more, the literature about treating anorexia nervosa is limited in general, as this type of ED is particularly difficult to treat. Nevertheless, third-generation therapies (Hayes, 2004) are beginning to be implemented to treat patients with anorexia nervosa (Berman, Boutelle, \& Crow, 2009; Heffner \& Eifert, 2004; Heffner, Sperry, Eifert, \& Detweiler, 2002; Wilson \& Roberts, 2002). However, research on such intervention is currently limited, as this treatment is relatively new. Such understanding of psychopathology as being of a radically contextual nature is allowing for severe, refractory problems to be approached in a calm and tremendously effective manner. In the present clinical case, we observed that implementing these strategies achieved very significant changes. An attempt was made to monitor the variables related to therapeutic behavior by using video and having several observers record the sessions. This study contributes to the scarce body of literature currently available on third-generation treatments of severe pathologies such as anorexia nervosa and suggests this type of clinical strategy could be useful in treating disorders that usually resist treatment such as in the present case, as they do not concentrate exclusively or necessarily on the pathognomonic behavioral criteria in diagnosis, instead dealing with an array of problems in the patient's daily life, as expressed in the therapeutic relationship itself. The usual limitations of this type of experimental design could have been partially mitigated by employing a between-subjects, concurrent, multiple-baseline design, which is being used in our current research.

\section{2 Recommendations to Clinicians and Students}

There are very systematic data available on FAP and ACT, the processes they involved and their outcomes, and an abundance of research on the basic procedures used in these therapies such as stimulus control, rule learning, reinforcement, and experiential avoidance. We recommend that students and clinicians alike consider these strategies and their underlying philosophy from the perspective of radical behaviorism, as it can contribute to effectively treating difficult, treatmentresistant patients such as those diagnosed with anorexia nervosa and personality disorders. These strategies are described extremely well in a manual by Heffner and Eifert (2004) as well as by Kohlenberg and Tsai $(1991,1994)$. For information about the basic philosophy, applied to several clinical examples, refer to Hayes et al. (1999) or Hayes, Follette, and Linehan (2004). It has become clear that these approaches can be useful in ED patients resistant to traditional CBT, yet, further research is required. The present case study suggests that ACT and FAP show great promise for intervention in treatment-resistant patients with anorexia nervosa. 


\section{Acknowledgments}

The authors would like to thank the clinical and health psychology master's degree students (University of Almeria) Francisco Peña, Esperanza Peláez, Maite Locubiche, Rocío Garriga, Belén López, Begoña Gallardo, Lola Saura, Joaquin Valdes, Mari Angeles Mellado, Macarena García, and researcher Eugenia Pozo.

\section{Declaration of Conflicting Interests}

The author(s) declared no potential conflicts of interest with respect to the research, authorship, and/or publication of this article.

\section{Funding}

The author(s) received no financial support for the research, authorship, and/or publication of this article.

\section{References}

Agras, W. S., Brandt, H. A., Bulik, C. M., Dolan-Sewell, R., Fairburn, C. G., Halmi, K. A., . . Wilfley, D. E. (2004). Report of the National Institutes of Health workshop on overcoming barriers to treatment research in anorexia nervosa. International Journal of Eating Disorders, 35, 509-521. doi:10.1002/eat.10261

American Psychiatric Association. (2000). Diagnostic and statistical manual of mental disorders (4th ed., text rev.). Washington, DC: Author.

Berman, M. I., Boutelle, K. N., \& Crow, S. J. (2009). A case series investigating ACT therapy as a treatment for previously treated, unremitted patients with AN. European Eating Disorder Review, 17, 426-434.

Fairburn, C. G. (2005). Evidence-based treatment of anorexia nervosa. International Journal of Eating Disorders, 37, 526-530.

Garner, D. M. (1998). Eating Disorder Inventory-2 [Spanish version]. Madrid, Spain: TEA Ediciones.

Hayes, S. C. (2004). Acceptance and commitment therapy and the new behavior therapies. In S. C. Hayes, V. M. Follette, \& M. M. Linehan (Eds.), Mindfulness and acceptance: Expanding the cognitive-behavioral tradition (pp. 5-29). New York, NY: Guilford.

Hayes, S. C., Follette, V. M., \& Linehan, M. M. (2004). Mindfulness and acceptance: Expanding the cognitive-behavioral tradition. New York, NY: Guilford.

Hayes, S. C., Strosahl, K. D., \& Wilson, K. G. (1999). Acceptance and commitment therapy. New York, NY: Guilford.

Heffner, M., \& Eifert, G. H. (2004). The Anorexia Workbook: How to accept yourself, heal suffering, and reclaim your life. Oakland, CA: New Harbinger.

Heffner, M., Sperry, J. A., Eifert, G. H., \& Detweiler, M. (2002). Acceptance and commitment therapy in the treatment of anorexia nervosa: A case example. Cognitive and Behavioral Practice, 9, 232-236.

Karbasi, A. L. (2010). Enhanced cognitive-behavioral therapy (CBT-E) for eating disorders: Case study of a client with anorexia nervosa. Clinical Case Studies, 9, 225-240.

Kohlenberg, R. J., \& Tsai, M. (1991). Functional analytic psychotherapy: Creating intense and curative therapeutic relationships. New York, NY: Plenum.

Kohlenberg, R. J., \& Tsai, M. (1994). Functional analytic psychotherapy: A behavioral approach to treatment and integration. Journal of Psychotherapy Integration, 4, 175-201.

Linehan, M. (1993). Skills training manual for treating borderline personality disorder. New York, NY: Guilford.

Martín-Murcia, F., Cangas, A. J., Pozo, E., \& Martínez, M. (2010). Role of social support and family relationships in the eating disorders progression. Revista de Psicopatología y Salud Mental del Niño y del Adolescente, 15, 63-73.

Martín-Murcia, F., Cangas, A. J., Pozo, E., Martínez, M., \& López, M. (2008). Eating disorders and personality: A comparative study. Behavioral Psychology, 16, 187-203. 
Mehler, P. S., \& Andersen, A. E. (1999). Eating disorders: A guide to medical care and complications. Baltimore, MD: Johns Hopkins University Press.

Millon, T. (2007). Clinical Multiaxial Inventory-III [Spanish version]. Madrid, Spain: TEA Ediciones.

Ro, O., Martinsen, E., Hoffart, A., \& Rosenvinge, J. (2005). Two-year prospective study of personality disorders in adults with longstanding eating disorders. International Journal of Eating Disorders, 37, 112-118.

Rosenvinge, J., Martinussen, M., \& Ostensen, E. (2000). The comorbidity of eating disorders and personality disorders: Meta-analytic review of studies published between 1983 and 1998. Eating and Weight Disorders, 5, 52-61.

Segal, Z., Williams, J., \& Teasdale, J. (2002). Mindfulness-based cognitive therapy for depression: A new approach to preventing relapse. New York, NY: Guilford.

Wilson, K. G., \& Roberts, M. (2002). Core principles in acceptance and commitment therapy: An application to anorexia. Cognitive and Behavioral Practice, 9, 237-243.

\section{Bios}

Francisco Martín-Murcia is a clinical psychologist at a private practice, a consultant for the Association Against Anorexia and Bulimia, and a doctoral researcher of the treatment of eating and personality disorders at the Department of Personality, Evaluation, and Psychological Treatment (University of Almeria, Spain).

Adolfo J. Cangas Díaz is a professor in the Department of Personality, Evaluation, and Psychological Treatment (University of Almeria, Spain).

Luisa Pardo Gonzalez is a clinical psychologist at a private practice and a doctoral researcher of personality disorders (University of Almeria, Spain). 